significantly associated with FIT FOBT, screening procedure, male gender and endoscopist. Mean adenoma per procedure was 1.26 (range by endoscopist 0.95 - 2.01). ProxADR was significantly associated with age, FIT FOBT, screening procedure, male gender and endoscopist. AdvADR was significantly associated with age, FIT FOBT, screening procedure and endoscopist.

Conclusion Serrated polyp detection appears to be dependent on the endoscopist related factors. We found a four-fold difference in SPDR between the highest and lowest detectors and 4-5 fold difference in the mean number of serrated polyps per procedure, even in high performing bowel cancer screening accredited colonoscopists. SPDR was not associated with patient related factors and did not appear to be influenced by the use of high definition endoscopes. An SPDR of $31.9 \%$ is the highest reported detection rate by an endoscopist in a screening population and may inform future benchmark setting for SPDR KPI.

\section{P31 HEMOSPRAY IN THE TREATMENT OF VARICEAL BLEEDS: OUTCOMES FROM THE INTERNATIONAL HEMOSPRAY REGISTRY}

\footnotetext{
1,2 Mohamed Hussein*, ${ }^{1}$ Durayd Alzoubaidi, ${ }^{3}$ Michael Weaver, ${ }^{2}$ Christwishes Makahamadze, ${ }^{4}$ Alvaro de la Serna, ${ }^{5}$ Jacobo Ortiz Fernandez Sordo, ${ }^{6}$ Johannes W Rey, ${ }^{7}$ Bu Hayee, ${ }^{8}$ Edward Despott, ${ }^{8}$ Alberto Murino, ${ }^{9}$ Sulleman Moreea, ${ }^{10}$ Phil Boger, ${ }^{11}$ Jason Dunn, ${ }^{12}$ Inder Mainie, ${ }^{2}$ David Graham, ${ }^{3}$ Dan Mullady, ${ }^{3}$ Dayna Early, ${ }^{5}$ Krish Ragunath, ${ }^{13}$ John Anderson, ${ }^{14}$ Pradeep Bhandari, ${ }^{15}$ Martin Goetz, ${ }^{4}$ Enrique Rodriguez, ${ }^{16}$ Tamas Gonda, ${ }^{6}$ Ralf Kiesslich, ${ }^{17}$ Emmanuel Coron, ${ }^{1,2}$ Laurence B Lovat, ${ }^{1,2}$ Rehan Haidry. ${ }^{1}$ University College London, UK; ${ }^{2}$ University College London Hospital, UK; ${ }^{3}$ Washington University School of Medicine, USA; ${ }^{4}$ Hospital Universitario Ramón y Cajal, Spain; ${ }^{5}$ Nottingham University Hospitals, UK; ${ }^{6}$ Horst Scmidt Kliniken, Germany; ${ }^{7}$ Kings College Hospital, UK; ${ }^{8}$ Royal Free Hospital, UK; ${ }^{9}$ Bradford Hospital, UK; ${ }^{10}$ University Hospital Southampton, UK; ${ }^{11}$ Guys and St Thomas Hospital, UK; ${ }^{12}$ Belfast Health and Social Care Trust, UK; ${ }^{13}$ Gloucestershire Hospitals, UK; ${ }^{14}$ University of Portsmouth, UK; ${ }^{15}$ Klinikum Sindelfingen-Böblingen, UK; ${ }^{16}$ Columbia University, USA; ${ }^{17}$ University Hospital of Nantes, France
}

\subsection{6/gutjnl-2020-bsgcampus. 106}

Introduction Early treatment for variceal bleeding is recommended within 12 hours to improve outcomes. Endoscopic therapy in acute variceal bleeding can be technically difficult and not always successful and a bridge is sometimes required towards definitive therapy. Aim of this study was to look at outcomes in patients with upper gastrointestinal bleeds (UGIB's) secondary to varices.

Methods Data was collected prospectively (Jan'16- Nov'19) from 16 centres in the USA, UK, Germany, France and Spain. Hemospray was used during emergency endoscopy for a variceal UGIB as a monotherapy, dual therapy or rescue therapy once standard methods have failed. Haemostasis was defined as cessation of bleeding within 5 minutes.

Results 12 patients had Hemospray treatment following a variceal UGIB (10 male, 2 female). 10 oesophageal varices, 2 gastric varices. The median Rockall was 8 (IQR, 7-8). The median Blatchford was 15 (IQR, 13-17).

The immediate haemostasis rate was $75 \%$. There were no re-bleeds. 4 patients were treated with Hemospray monotherapy, 3 with combination therapy and 5 with rescue therapy. Hemospray was always given after oesophageal banding/injection sclerotherapy in the combination/rescue therapy cohorts. 4/9 patients died within 7 days, 3 out of these 4 patients did not achieve initial haemostasis with Hemospray.

Outcomes in the Hemospray subgroups (table 1).

\begin{tabular}{|c|c|c|c|}
\hline & Monotherapy $(n=4)$ & Combination $(n=3)$ & Rescue $(n=5)$ \\
\hline Median Blatchford score & $15($ IQR, 14-16) & $15(I Q R, 8-17)$ & $12($ IQR, 11-14) \\
\hline Median Rockall score & $8($ (IQR, 8-9) & $8(\mathrm{IQR}, 6-9)$ & $8($ IQR, 7-8) \\
\hline Haemostasis (\%) & $3 / 4(75 \%)$ & $2 / 3(66 \%)$ & $4 / 5(80 \%)$ \\
\hline \multicolumn{4}{|c|}{ Rockall 7 \& 8 predicted re-bleeding rate $25-40 \%$} \\
\hline Re-bleed & 0 & 0 & 0 \\
\hline \multicolumn{4}{|c|}{ Rockall 8 predicted mortality rate: $40-45 \%$} \\
\hline 7-day mortality (\%) & $1 / 3(33 \%)$ & $2 / 3(66 \%)$ & $1 / 3(33 \%)$ \\
\hline
\end{tabular}

Conclusions The immediate haemostasis rate was $75 \%$ in variceal UGIBs following treatment with Hemospray. In this cohort there is no re-bleeding. This suggests that Hemospray may play a role as bridging therapy in variceal bleeds which are difficult to control, towards repeat definitive therapy.

\section{P32 USE OF HEMOSPRAY IN THE TREATMENT OF LOWER GASTROINTESTINAL BLEEDS: OUTCOMES FROM THE HEMOSPRAY REGISTRY}

\begin{abstract}
1,2 Mohamed Hussein*, ${ }^{2}$ Durayd Alzoubaidi, ${ }^{3}$ Michael Weaver, ${ }^{2}$ Christwishes Makahamadze, ${ }^{4}$ Alvaro de la Serna, 5 Jacobo Ortiz Fernandez Sordo, ${ }^{6}$ Johannes W Rey, ${ }^{7}$ Bu Hayee, ${ }^{8}$ Edward Despott, ${ }^{8}$ Alberto Murino, ${ }^{9}$ Sulleman Moreea, ${ }^{10}$ Phil Boger, ${ }^{11}$ Jason Dunn, ${ }^{12}$ Inder Mainie, ${ }^{2}$ David Graham, ${ }^{3}$ Dan Mullady, ${ }^{3}$ Dayna Early, ${ }^{5}$ Krish Ragunath, ${ }^{13} J o h n$ Anderson, ${ }^{14}$ Pradeep Bhandari, ${ }^{15}$ Martin Goetz, ${ }^{4}$ Enrique Rodriguez, ${ }^{16}$ Tamas Gonda, ${ }^{5}$ Ralf Kiesslich, ${ }^{17}$ Emmanuel Coron, ${ }^{1,2}$ Laurence B Lovat, ${ }^{1,2}$ Rehan Haidry. ${ }^{1}$ University College London, UK; ${ }^{2}$ University College London Hospital, UK; ${ }^{3}$ Washington University School of Medicine, USA; ${ }^{4}$ Hospital Universitario Ramón y Cajal, Spain; ${ }^{5}$ Nottingham University Hospitals, UK; ${ }^{6}$ Horst Scmidt Kliniken, Germany; ${ }^{7}$ Kings College Hospital, UK; ${ }^{8}$ Royal Free Hospital, UK; ${ }^{9}$ Bradford Hospital, UK; ${ }^{10}$ University Hospital Southampton, UK; ${ }^{11}$ Guys and St Thomas Hospitals, UK; ${ }^{12}$ Belfast Health and Social Care Trust, UK; ${ }^{13}$ Gloucestershire Hospitals, UK; ${ }^{14}$ University of Portsmouth, UK; ${ }^{15}$ Klinikum Sindelfingen-Böblingen, Germany; ${ }^{16}$ Columbia University, USA; ${ }^{17}$ University Hospital of Nantes, France
\end{abstract}

\subsection{6/gutjnl-2020-bsgcampus.107}

Introduction Lower Gastrointestinal bleeding (LGIB) accounts for $20 \%$ of GI bleeds, with significant mortality in the elderly and those with comorbidities. There is limited data on the use of Hemospray in LGIB's. The primary aim was to look at its safety and efficacy in the treatment of LGIB's.

Methods Data was prospectively collected on the use of Hemospray in LGIB's in 16 Centres in the UK, USA, Germany, France and Spain (January 2016 - November 2019). Hemospray was used as a monotherapy, combination therapy or rescue therapy. Haemostasis was defined as the cessation of bleeding within 5 minutes of Hemospray application.

Results 24 patients with LGIB's were recruited (16 male, 8 female). The cause of bleeding included malignancy (6/ 24,25\%), post procedure (polypectomy/ESD)(5/24,21\%), inflammation/angiodysplasia $(7 / 24,29 \%)$. The median lesion diameter was $20 \mathrm{~mm}$ (IQR, 25-50). 9/24 (38\%) patients were on antiplatelets/anticoagulants.

Immediate haemostasis was achieved in 22/24 (92\%) patients. 2/19 (11\%) had a re-bleed within 7 days, 4/19 (21\%) had a re-bleed within 30 days. 2/21 (10\%) died within 30 days (all cause mortality). The two patients that failed treatment had surgery. In combination Hemospray was always used as a second or third modality. There was a 78\% haemostasis rate in patients on anticoagulants/antiplatelets, $100 \%$ immediate haemostasis on patients on no anticoagulants. 


\begin{tabular}{llll} 
Abstract P32 Table 1 & & \\
\hline & Monotherapy $(\mathrm{n}=15)$ & Combination $(\mathrm{n}=8)$ & Rescue $(\mathrm{n}=\mathbf{1})$ \\
\hline Haemostasis & $15 / 15(100 \%)$ & $7 / 8(88 \%)$ & $0 / 1$ \\
Re-bleeding & $3 / 13(23 \%)$ & $1 / 6(17 \%)$ & $\mathrm{n} / \mathrm{a}$ \\
7-day mortality & $1 / 13(8 \%)$ & 0 & 0 \\
30-day mortality & $2 / 13(15 \%)$ & 0 & 0 \\
\hline
\end{tabular}

There were no adverse events associated with Hemospray.

Outcomes in the Hemospray treatment subgroups (table 1). Conclusions Hemospray is safe and effective in LGIB's with 92\% haemostasis rates, with better outcomes as a Monotherapy. Anticoagulants have an effect on haemostasis rates $(78 \%$ vs $100 \%)$.

Lower GI bleeds are difficult to treat. Hemospray is an effective alternative in situations where access is difficult and there is a large surface of bleeding.

\section{P33 HEMOSPRAY TREATMENT IN NON-VARICEAL UPPER GASTROINTESTINAL BLEEDS: OUTCOMES FROM THE FIRST 500 HEMOSPRAY REGISTRY PATIENTS}

\footnotetext{
1,2 Mohamed Hussein*, 'Durayd Alzoubaidi, ${ }^{3}$ Michael Weaver, ${ }^{2}$ Christwishes Makahamadze, ${ }^{4}$ Alvaro de la Serna, ${ }^{5}$ Jacobo Ortiz Fernandez Sordo, ${ }^{6}$ Johannes W Rey, ${ }^{7}$ Bu Hayee, ${ }^{8}$ Edward Despott, ${ }^{8}$ Alberto Murino, ${ }^{9}$ Sulleman Moreea, ${ }^{10}$ Phil Boger, ${ }^{11}$ Jason Dunn, ${ }^{12}$ Inder Mainie, ${ }^{2}$ David Graham, ${ }^{3}$ Dan Mullady, ${ }^{3}$ Dayna Early, ${ }^{5}$ Krish Ragunath, ${ }^{13}$ John Anderson, ${ }^{14}$ Pradeep Bhandari, ${ }^{15}$ Martin Goetz, ${ }^{4}$ Enrique Rodriguez, ${ }^{16}$ Tamas Gonda, ${ }^{5}$ Ralf Kiesslich, ${ }^{17}$ Emmanuel Coron, ${ }^{1,2}$ Laurence B Lovat, ${ }^{1,2}$ Rehan Haidry. ${ }^{1}$ University College London, UK; ${ }^{2}$ University College London Hospital, UK; ${ }^{3}$ Washington University School of Medicine, USA; ${ }^{4}$ Hospital Universitario Ramón y Cajal, Spain; ${ }^{5}$ Nottingham University Hospitals, UK; ${ }^{6}$ Horst Scmidt Kliniken, Germany; ${ }^{7}$ Kings College Hospital, UK; ${ }^{8}$ Royal Free Hospital, UK; ${ }^{9}$ Bradford Hospital, UK; ${ }^{10}$ University Hospital Southampton, UK; ${ }^{11}$ Guys and St Thomas Hospital, UK; ${ }^{12}$ Belfast Health and Social Care Trust, UK; ${ }^{13}$ Gloucestershire Hospitals, UK; ${ }^{14}$ University of Portsmouth, UK; ${ }^{15} \mathrm{Klinikum}$ Sindelfingen-Böblingen, Germany; ${ }^{16}$ Columbia University, USA; ${ }^{17}$ University Hospital of Nantes, France
}

\subsection{6/gutjnl-2020-bsgcampus. 108}

Introduction Upper gastrointestinal bleeding (UGIB) is a leading cause of morbidity. The aim was to look at outcomes in patients with non-variceal UGIBs of all causes treated with Hemospray.

Methods Data was collected prospectively (Jan' 16- Nov'19) from 16 centres in the USA, UK, Germany, France and Spain. Hemospray was used during endoscopy as a monotherapy, dual therapy or rescue therapy. Haemostasis was defined as cessation of bleeding within 5 minutes of Hemospray application.

Results 512 patients with non-variceal UGIBs were recruited (343 male, 169 female). The most common cause was peptic ulcers $(236 / 512,46 \%)$.

Immediate haemostasis was achieved in 473/512 (92\%) patients. Median Blatchford was 11 (IQR, 8-14), median Rockall was 7 (IQR, 6-8). Re-bleeding occurred in 59/404 (15\%) patients. There was a 7-day mortality (all cause) of $9 \%$ (42/444), 30-day mortality (all cause) was 19\% (85/444). The highest haemostasis rates were in the Hemospray monotherapy group (95\%).

39 patients did not achieve haemostasis (69\% were peptic ulcer related). 14/39 (36\%) of these patients had CT embolization, $7 / 39(18 \%)$ managed conservatively and 3/39 (8\%) had surgery.

\begin{tabular}{llllll} 
Abstract P33 & Table1 & & & \\
\hline & $\begin{array}{l}\text { Peptic } \\
\text { ulcers } \\
(\mathbf{n}=236)\end{array}$ & $\begin{array}{l}\text { Malignancy } \\
(\mathbf{n}=96)\end{array}$ & $\begin{array}{l}\text { Post } \\
\text { procedure } \\
(\mathbf{n}=73)\end{array}$ & $\begin{array}{l}\text { Inflammation } \\
(\mathbf{n}=20)\end{array}$ & $\begin{array}{l}\text { Angiodysplasia } \\
(\mathbf{n}=12)\end{array}$ \\
\hline $\begin{array}{l}\text { Median } \\
\text { Blatchford }\end{array}$ & $13(10-$ & $10(7-12)$ & $5(0-9)$ & $9(7-14)$ & $11(9-11)$ \\
(IQR) & & & & & \\
$\begin{array}{l}\text { Median Rockall } \\
\text { (IQR) }\end{array}$ & $7(6-8)$ & $8(7-9)$ & $6(5-7)$ & $7(6-8)$ & $6(5-7)$ \\
Haemostasis & $209 / 236$ & $93 / 96$ & $73 / 73$ & $19 / 20$ & $12 / 12$ \\
& $(89 \%)$ & $(97 \%)$ & $(100 \%)$ & $(95 \%)$ & $(100 \%)$ \\
Re-bleed & $34 / 181$ & $11 / 78$ & $2 / 57$ & $2 / 17$ & $2 / 11$ \\
& $(19 \%)$ & $(14 \%)$ & $(4 \%)$ & $(12 \%)$ & $(18 \%)$ \\
7-day mortality & $24 / 208$ & $2 / 81$ & $1 / 59$ & $4 / 18$ & 0 \\
& $(12 \%)$ & $(2 \%)$ & $(2 \%)$ & $(22 \%)$ & \\
30-day & $48 / 208$ & $16 / 81$ & $1 / 59$ & $6 / 18$ & 0 \\
mortality & $(23 \%)$ & $(20 \%)$ & $(2 \%)$ & $(33 \%)$ & \\
\hline
\end{tabular}

Outcomes in different UGI pathologies (table 1).

Conclusion There were high immediate haemostasis rates following treatment of non-variceal UGIBs. The better outcomes were when Hemospray was used in UGIB's post endotherapy, malignancy and Angiodysplasia. In malignancies it can bridge towards surgery/chemoradiotherapy, and post endotherapy it can provide definitive haemostasis with low re-bleed rates.

\section{P34 EFFECT OF BOWEL PREPARATION ON RENAL FUNCTION IN PATIENTS WITH AND WITHOUT CHRONIC KIDNEY DISEASE}

Ben Johnson*, Vanja Giljaca. University Hospitals Birmingham, Birmingham, UK

\subsection{6/gutjnl-2020-bsgcampus.109}

Aims Records for patients who underwent colonoscopy and who received a $2 \mathrm{~L}$ polyethylene glycol (PEG) bowel preparation were reviewed to evaluate whether there is any effect on renal function in those patients with chronic kidney disease (CKD) versus those without.

Methods We screened 1000 randomly chosen patients from a pool of 2128 colonoscopies in 2017. Data were collected on quality of bowel preparation, history of $\mathrm{CKD}$, and creatinine and an estimated glomerular filtration rate (eGFR) in the 60 days before and after colonoscopy. Patients with CKD were defined as those patients with a documented diagnosis or an eGFR of less than 60 for more than 3 months.

Results Bowel preparation quality was good or excellent in $41 \%$ of patients. Out of 1,000 patients, only $20.9 \%$ (n = 209) had their renal function checked both 60 days before

\section{Abstract P34 Table 1}

\begin{tabular}{llll}
\hline & $\begin{array}{l}\text { No. of } \\
\text { Patients }\end{array}$ & $\begin{array}{l}\text { \% Creatinine } \\
\text { Change }\end{array}$ & $\begin{array}{l}\text { \% eGFR } \\
\text { Change }\end{array}$ \\
\hline Patients with CKD & 58 & $4.70 \%$ & $2.60 \%$ \\
Patients without CKD & 151 & $1.30 \%$ & $0.05 \%$ \\
Significance of\% Change in CKD vs & & $\mathrm{p}=0.18$ & $\mathrm{p}=0.18$ \\
Non-CKD & & & \\
\hline
\end{tabular}

